\title{
Clinical efficiency of combination therapy using testosterone replacement therapy, phosphodiesterase 5 inhibitors and Kampo herbal medicine for eugonadal patients with late-onset hypogonadism syndrome
}

\author{
HISASHI TAKEUCHI ${ }^{1-3}$ and HIDENORI OKUBO ${ }^{1}$ \\ ${ }^{1}$ Department of Urology, Kyoeikai Okubo Hospital, Mitoshi, Ibaraki 310-0905; \\ ${ }^{2}$ Department of Urology, Tokyo International Ohori Hospital, Tokyo 181-0013, Japan
}

Received January 3, 2020; Accepted June 17, 2020

DOI: 10.3892/etm.2021.10608

\begin{abstract}
In the present study, the initial treatment efficiency of combination therapy using testosterone replacement therapy (TRT), herbal medicine and phosphodiesterase 5 inhibitors (PDE5i) in male patients with late-onset hypogonadism $(\mathrm{LOH})$ were assessed. A total of 21 patients were enrolled and after 12 weeks, the clinical efficacy was evaluated based on improvement of LOH symptoms via laboratory parameters and several questionnaires, including the Ageing Males' Symptoms (AMS) scale. The overall AMS scores, as well as the psychological, physical and sexual AMS factors prior to and after treatment in the TRT, testosterone enanthate (T enanthate) monotherapy and T enanthate + PDE5i treatment groups were significantly improved. In the herbal medicine group, only the AMS physiological factors were significantly improved after treatment compared with the baseline. The improvement of the overall AMS scores, as well as the physiological and sexual AMS factors, were significantly negatively correlated with the free testosterone (FT) value prior to treatment. In conclusion, treatment with combination therapy using TRT, herbal medicine and PDE5i improved AMS scores in patients with LOH syndrome. Particularly in patients with LOH syndrome and low FT, the symptoms were significantly improved following combination therapy.
\end{abstract}

\section{Introduction}

Late-onset hypogonadism ( $\mathrm{LOH}$ ) syndrome is an endocrine disorder that is characterized by low levels of androgen and

Correspondence to: Dr Hisashi Takeuchi, ${ }^{3}$ Present address: Department of Urology, IMS Group, Shinmatsudo Central General Hospital, Shinmatsudo 1-380, Matsudo, Chiba 270-0034, Japan E-mail: hisashi917@yahoo.co.jp

Key words: herbal medicine, Kampo, late-onset hypogonadism syndrome, testosterone replacement therapy, sexual function, urinary disfunction, anti-ageing therapy a subsequent decline in various physical functions (1). LOH syndrome has a well-established concept of disorder in men, but what differentiates it from the so-called 'menopausal disorders' is that testosterone levels included into the diagnostic criteria (1).

In males, serum testosterone levels remain stable until $\sim 40$ years of age, after which the circulating total testosterone and biologically active free testosterone (FT) levels decrease by $1-2$ and $2-3 \%$ annually, respectively $(2,3)$. Testosterone is strongly bound to sex hormone-binding globulin (SHBG) and relatively loosely bound to albumin. The subsequent addition of FT to these hormones gives the total testosterone (TT). Furthermore, since albumin-bound testosterone and FT are biologically meaningful, they are referred to as bioavailable testosterone.

The diagnosis of LOH syndrome is based on serum testosterone levels, taking clinical symptoms and signs into account. The European Endocrine Society and the International Society for the Study of the Ageing Male recommend measuring TT (4). In Japan, serum FT levels are used as the diagnostic criterion for LOH syndrome (5), as Okamura et al (6) and Iwamoto et al (7) reported that TT does not change with age. Furthermore, it has also been reported that LOH-associated symptoms are not significantly associated with serum levels of TT, analog ligand FT, estradiol, luteinizing hormone (LH), follicle-stimulating hormone ( $\mathrm{FSH})$, dehydroepiandrosterone sulfate or growth hormone (8).

Regarding the treatment of $\mathrm{LOH}$ syndrome, the use of several agents, primarily testosterone replacement therapy (TRT), has been reported (9). TRT includes administration of oral, injectable and skin-absorbing agents, but in Japan, only testosterone enanthate ( $\mathrm{T}$ enanthate) injection is covered by insurance, and $125-250 \mathrm{mg}$ is usually injected intramuscularly every 2 weeks. In Europe and the USA, an increasing number of patients prefer gels (9).

The effects of TRT include improvements in muscle mass, strength, bone density, serum fat profile, insulin sensitivity, libido and overall health (10). For erectile dysfunction, TRT was determined to increase the effect of phosphodiesterase 5 inhibitors (PDE5i) (11). In a meta-analysis of clinical trials on TRT, the frequency of adverse events in which prostate cancer 
occurs in association with TRT did not change between the TRT treatment group and the placebo group (12). However, certain patients with low testosterone levels had high-grade malignancies despite relatively low prostate-specific antigen (PSA) levels (13). Therefore, in accordance with Japanese guidelines, PSA is measured; if it is $2.0 \mathrm{ng} / \mathrm{ml}$ or higher, the patient should be referred to a urologist to rule out prostate cancer (5). $\mathrm{LOH}$ syndrome may lead to a decline in numerous biological functions linked to activities of daily living (ADL) and quality of life (QOL), including cognitive function, muscle strength, bone density, sexual function and metabolism (14-17). Approximately $20 \%$ of males over 60 years of age may have LOH syndrome. These patients may improve their ADL and prevent lifestyle-related diseases (LRDs) such as metabolic syndrome via TRT (16). In a double-blind clinical trial, 1,677 local residents aged 65 years or above were screened, of which 274 patients with a weak constitution, weight loss, low exercise, muscle weakness, fatigue, slow walking and serum testosterone levels $<345 \mathrm{ng} / \mathrm{dl}$, who had no prostate disease or dysuria, were randomly assigned to the testosterone gel (50 mg/day) treatment group and the placebo group (18). The results indicated a significant increase in knee joint muscle strength, increased body mass index (BMI), decreased fat mass, improved physical function, and improved QOL index (physical symptoms, sexual function symptoms) within six months in the TRT treatment group (18).

In addition to TRT, certain therapies for $\mathrm{LOH}$ syndrome commonly include counseling, antidepressants, PDE5i and herbal medicine (Kampo). Various herbal medicines have been used to treat LOH syndrome (19). Tsujimura et al (20) recently reported on herbal medicine as a possible treatment option.

Oxidative stress is cited as a cause of various diseases. Oxidative stress, and occasionally anticancer activity (21), are useful biomarkers for predicting severe erectile dysfunction (ED) and $\mathrm{LOH}$ syndrome in middle-aged males. Therefore, PDE5i may improve LOH syndrome symptoms, as PDE5i has been demonstrated to increase testosterone through its antioxidant activity $(22,23)$. Amano et al (24) reported that testosterone ointment (Glowmin; DAITO Pharmaceutical Co.) applied to patients with LOH syndrome for three months significantly improved their functional capacity and their psychological and mental health.

In the present study, the effectiveness of initial treatment by combination therapy using TRT, herbal medicine and PDE5i in male patients with $\mathrm{LOH}$ were determined. The patients' clinical background, changes in symptom scores and clinical parameters were analyzed to verify the effectiveness of the treatment intervention.

\section{Patients and methods}

Patients. Between April 2017 and September 2018, 21 patients with LOH-associated symptoms, including chief complaints of decreased libido, ED, depression and general fatigue, visited the menopausal outpatient clinic at Kyoei-kai Okubo Hospital (Ibaraki, Japan). Those who had undergone previous treatments were included in the present study (Table I). No patients with any serious condition, such as malignancy, sleep apnea syndrome (SAS), suicidal depression or high PSA levels $(>2.0 \mathrm{ng} / \mathrm{ml})$, or who refused treatment, were included according to Japanese guidelines (5). All patients provided written informed consent to participate in the present study.

Examination. At their first visit, the patients were evaluated by reviewing their medical history, a physical examination and detection of clinical parameters, and their general LOH symptoms were judged according to Heinemann's Ageing Males' Symptoms (AMS) scale (25). Voiding function was evaluated by the International Prostate Symptom Score (IPSS) (26) and sexual function was evaluated by the International Index of Erectile Function-5 (IIEF-5) score. Blood screening, including hemoglobin $(\mathrm{Hb})$, aspartate transaminase, alanine transaminase, creatinine, total cholesterol (T-Cho), triglyceride, blood sugar and PSA, and endocrinological variables [including FT (RIA method), LH and FSH] were determined until 11 a.m. prior to monitoring endocrinological variables for any treatment of $\mathrm{LOH}$. The patients in the present study had not received any medications for $\mathrm{LOH}$, such as TRT, previously.

The questionnaire to determine the AMS score as a disease-specific measure was administered at baseline and after 12 weeks. The AMS score comprises 17 items scored on a five-point scale (25). The 17 items are distributed over three subdomains: A total of five questions address psychological factors, seven address physical factors and five address factors of sexual function. The total AMS score defines symptom severity as 'no/little' (17-26 points), 'mild' (27-36 points), 'moderate' (37-49 points) or 'severe' ( $\geq 50$ points) (25).

Furthermore, the IPSS questionnaire for lower urinary tract symptoms and IIEF-5 questionnaire for sexual function were also administered. The IPSS contains seven symptom questions that assess weak urine stream, intermittency and straining (voiding symptoms), frequency, urgency and nocturia (storage symptoms), and a feeling of incomplete bladder emptying (post-voiding symptom). The response options range from 'not at all' (0 points) to 'almost always' (5 points), with a maximum total of 35 points. The total IPSS score defines symptom severity as 'no/little' (0-7 points), 'moderate' (8-19 points) or 'severe' ( $\geq 20$ points) $(26)$. The IIEF-5 score comprises only five questions and each item is scored on a five-point ordinal scale, wherein lower values indicate poor sexual function. The possible IIEF-5 scores range from 1 to 25 points (one question may receive a score from 1 to 5 ; all others may receive scores from 0 to 5); a score of $>21$ points is considered to indicate normal erectile function, whereas scores at or below this cut-off indicate ED (27).

Metabolic syndrome (Mets) and the BMI have been reported to be related, so as an indicator of the potential Mets of the body type of individual patients (28), the BMI was calculated initially for each patient. According to the World Health Organization guidelines, a BMI $<25 \mathrm{~kg} / \mathrm{m}^{2}$ represents a normal body weight and a BMI $\geq 25 \mathrm{~kg} / \mathrm{m}^{2}$ represents overweight status (29). Thus, the patients were then grouped by their BMI-defined body type using a threshold value of $25 \mathrm{~kg} / \mathrm{m}^{2}$ (29). In addition, to determine the impact of diseases, such as LRDs or psychiatric disorders (PDs), that are closely linked to $\mathrm{LOH}$ syndrome, the patients were further divided into groups with or without LRDs or PDs (30). 
Table I. Clinical features of the patients with late-onset hypogonadism syndrome $(\mathrm{n}=21)$.

\begin{tabular}{|c|c|}
\hline Characteristic & Value \\
\hline Age (years) & $50(33-65)$ \\
\hline BMI $\left(\mathrm{kg} / \mathrm{m}^{2}\right)$ & $23.1(17.0-35.2)$ \\
\hline $\mathrm{FT}(\mathrm{pg} / \mathrm{ml})$ & $8.5(4.9-15.2)$ \\
\hline LH (mIU/ml) & $4.0(1.4-11.8)$ \\
\hline FSH (mIU/ml) & $2.5(1.1-7.3)$ \\
\hline PRL (ng/ml) & $3.0(3.5-64.9)$ \\
\hline $\mathrm{Hb}(\mathrm{g} / \mathrm{dl})$ & $15.4(12.9-16.8)$ \\
\hline T-Cho (mg/dl) & $196(152-319)$ \\
\hline AMS score & $51(36-68)$ \\
\hline IIEF5 score & $12(5-22)$ \\
\hline IPSS score & $6(0-28)$ \\
\hline PD (with/without) & $4 / 17$ \\
\hline LRD (with/without) & $9 / 12$ \\
\hline \multicolumn{2}{|l|}{ Treatment } \\
\hline TRT monotherapy & 14 \\
\hline $\mathrm{T}$ enanthate $250 \mathrm{mg}$ & 13 \\
\hline Testosterone ointment & 1 \\
\hline $\begin{array}{l}\text { TRT combination } \\
\text { (T enanthate } 250 \mathrm{mg}+\text { PDE5i) }\end{array}$ & 3 \\
\hline Herbal medicines & 4 \\
\hline Hochuekkito & 2 \\
\hline Kamishoyosan & 1 \\
\hline Shakuyakukanzoto & 1 \\
\hline
\end{tabular}

Values are expressed as median (range) or n. BMI, body mass index; PD, psychiatric disorders; LRD, lifestyle-related diseases; FT, free testosterone; FSH, follicle-stimulating hormone; PRL, prolactin; AMS, Ageing Males' Symptoms scale; IEF5, International Index of Erectile Function-5; IPSS, International Prostate Scale Score; PDE5i, phosphodiesterase 5 inhibitors; TRT, testosterone replacement therapy.

Treatment. After confirming the examination and blood test results, TRT or an oral treatment, such as herbal medicines or PDE5i, was provided for each symptom. For the TRT, T enanthate $\left(250 \mathrm{mg}\right.$; Enarmon Depot ${ }^{\circledR}$; ASKA Pharmaceutical Co., Ltd.) was administered via intramuscular injection every four weeks for a total of 12 weeks or testosterone ointment was applied to a $2.5-\mathrm{cm}$ area once a day. The most appropriate herbal medicine was administered to the patients according to their pathogenic alterations. A total of three traditional Japanese herbal medicines, namely Kamishoyosan (TJ-24), Hochuekkito (TJ-41) and Shakuyakukanzoto (TJ-68) (Tsumura \& Co.), were candidates for $\mathrm{LOH}$ treatment in the present study. The composition of each of these three herbal medicines is described in Table II. The basic selection criteria are presented in Table III. All herbal drugs were given orally 3 times a day (before meals) to a total dose of $7.5 \mathrm{~g} /$ day.

All treatments were repeated over 12 weeks from the start of treatment. Laboratory and endocrinological values and $\mathrm{LOH}$-related symptoms determined prior to and after treatment were compared to evaluate the efficacy and safety of the combination therapy for $\mathrm{LOH}$.

If patients wished to be further treated, their current treatment was continued or switched to another treatment, continued for another 12 weeks and then evaluated again via blood sample analyses. Those results were not included in the present study. There were no adverse events that required treatment interruption in any treatment group during the treatment period.

Statistical analysis. All statistical analyses were performed using StatView (version 5.0; SAS Institute, Inc.). Continuous variables were presented as the mean \pm SD or the median (range). Based on the AMS scores, the patients were categorized into three groups: None or mild (17-26 points and 27-36 points), moderate (37-49 points) and severe (50 points or more). The FT was also categorized into three groups: Low $(<8.5 \mathrm{pg} / \mathrm{ml})$, borderline zone $(\geq 8.5$ and $<11.8 \mathrm{pg} / \mathrm{ml})$ and normal $(\geq 11.8 \mathrm{pg} / \mathrm{ml})$. In addition, the IPSS scores were categorized into three groups: Mild (0-7 points), moderate (8-19 points) and severe (20 points or more). A $\chi^{2}$ test was used to compare the age, FT and the presence of PD and LRD among groups stratified by their AMS score. An unpaired t-test was used to compare clinical features, including the AMS score, age, FT, BMI, IPSS score, IIEF-5 score, and with LRD groups. Correlations among various clinical parameters were determined using the Spearman's rank correlation test (Figs. 5 and 7). $\mathrm{P}<0.05$ was considered to indicate statistical significance.

\section{Results}

Clinical features and patient treatment. The clinical characteristics of the 21 patients with $\mathrm{LOH}$ syndrome are presented in Table I. The median patient age was 50 years (range, $33-65$ years). The median BMI was $23.1 \mathrm{~kg} / \mathrm{m}^{2}$ (range, 17.0-35.2 kg/m²) and the median AMS score was 51 (range, 36-68). Only 9 of the 21 patients had an LRD.

The treatment details are as follows: TRT monotherapy in 14 cases ( $T$ enanthate $250 \mathrm{mg}$ in 13 cases, testosterone ointment in 1 case), TRT ( $\mathrm{T}$ enanthate $250 \mathrm{mg}+$ PDE5i) in 3 cases and herbal medicines in 4 cases (Hochuekkito in 2 cases, Kamishoyosan in 1 case and Shakuyakukanzoto in 1 case) (Table I).

Comparison of AMS score and age, FT, PDs and LRDs. As presented in Table IV, the patients were stratified based on the AMS scores into mild, moderate and severe groups, and it was examined whether there was any bias in any of the groups in terms of age (cut-off, 50, 55 years), FT (low, borderline zone and normal), and the presence or absence of PDs and LRDs by using the $\chi^{2}$ test. There was no significant difference among any of the groups.

Comparison of FT and BMI and IPSS score. As presented in Table V, the FT values were divided into low, borderline and normal groups, and it was examined whether there was any bias among the groups regarding the BMI (cut-off, $25 \mathrm{~kg} / \mathrm{m}^{2}$ ) and IPSS score (no/little, moderate and severe). There was no significant bias among the groups. 
Table II. Composition of the three herbal medicines for the treatment of late-onset hypogonadism syndrome.

\begin{tabular}{|c|c|c|}
\hline Name & Preparation & Herbal components \\
\hline Kamishoyosan (TJ-24) & $\begin{array}{l}7.5 \mathrm{~g} \text { of extract granules contain } 4.0 \mathrm{~g} \text { of a dried extract of } \\
\text { the mixed crude herbs. }\end{array}$ & $\begin{array}{l}\text { Bupleurum root, } 3.0 \mathrm{~g} \\
\text { Peony root, } 3.0 \mathrm{~g} \\
\text { Atractylodes lancea rhizome, } 3.0 \mathrm{~g} \\
\text { Angelica root, } 3.0 \mathrm{~g} \\
\text { Poria sclerotium, } 3.0 \mathrm{~g} \\
\text { Gardenia fruit, } 2.0 \mathrm{~g} \\
\text { Moutan bark, } 2.0 \mathrm{~g} \\
\text { Glycyrrhiza, } 1.5 \mathrm{~g} \\
\text { Ginger, } 1.0 \mathrm{~g} \\
\text { Mentha herb, } 1.0 \mathrm{~g}\end{array}$ \\
\hline Hochuekkito (TJ-41) & $\begin{array}{l}7.5 \mathrm{~g} \text { of extract granules contain } 5.0 \mathrm{~g} \text { of a dried extract of } \\
\text { the mixed crude herbs. }\end{array}$ & $\begin{array}{l}\text { Astragalus root, } 4.0 \mathrm{~g} \\
\text { Atractylodes lancea rhizome, } 4.0 \mathrm{~g} \\
\text { Ginseng, } 4.0 \mathrm{~g} \\
\text { Angelica root, } 3.0 \mathrm{~g} \\
\text { Bupleurum root, } 2.0 \mathrm{~g} \\
\text { Jujube, } 2.0 \mathrm{~g} \\
\text { Citrus unshiu peel, } 6.0 \mathrm{~g} \\
\text { Glycyrrhiza, } 1.5 \mathrm{~g} \\
\text { Cimicifuga rhizome, } 1.0 \mathrm{~g} \\
\text { Ginger, } 0.5 \mathrm{~g}\end{array}$ \\
\hline Shakuyakukanzoto (TJ-68) & $\begin{array}{l}7.5 \mathrm{~g} \text { of extract granules contain } 2.5 \mathrm{~g} \text { of a dried extract of } \\
\text { the mixed crude herbs. }\end{array}$ & $\begin{array}{l}\text { Peony root, } 6.0 \mathrm{~g} \\
\text { Glycyrrhiza, } 6.0 \mathrm{~g}\end{array}$ \\
\hline
\end{tabular}

Table III. Index for the selection of herbal medicine corresponding to the conditions of patients with late-onset hypogonadism syndrome.

\begin{tabular}{|c|c|}
\hline Formulation & Conditions \\
\hline Kamishoyosan (TJ-24) & $\begin{array}{l}\text { Shoulder stiffness, fatigue, } \\
\text { anxiety }\end{array}$ \\
\hline Hochuekkito (TJ-41) & $\begin{array}{l}\text { Severe fatigue, pollakisuria, } \\
\text { erectile dysfunction }\end{array}$ \\
\hline Shakuyakukanzoto (TJ-68) & $\begin{array}{l}\text { Relief of pain, myalgia, } \\
\text { arthralgia, gastric pain, } \\
\text { abdominal pain }\end{array}$ \\
\hline
\end{tabular}

Associations between AMS score and various clinical parameters. Differences in AMS scores between groups stratified based on various parameters were examined using Student's t-test (Fig. 1). There was no significant difference between the average AMS value between age groups stratified with a cutoff at 50 and 55 years. There was also no significant difference in the average AMS value between the normal-BMI $\left(<25 \mathrm{~kg} / \mathrm{m}^{2}\right)$ and high-BMI ( $\geq 25 \mathrm{~kg} / \mathrm{m}^{2}$ ) groups. There was also no significant difference in the average AMS value between patients with different FT values stratified with a cutoff at 8.5 and $11.8 \mathrm{pg} / \mathrm{ml}$. (psychological, physiological and sexual function). The
Table IV. Comparison of AMS score between patients stratified by age, FT, psychiatric disorders and LRDs ${ }^{\mathrm{a}}$ before treatment.

\begin{tabular}{lcccr}
\hline Factor & $<37$ & $37-50$ & $>50$ & Total \\
\hline Age (years) & & & & \\
$\geq 55$ & 0 & 2 & 5 & 7 \\
$50-54$ & 0 & 1 & 4 & 5 \\
$<50$ & 1 & 3 & 5 & 9 \\
FT (pg/ml) & & & & \\
$>11.8$ & 0 & 0 & 3 & 3 \\
$8.5-11.8$ & 1 & 3 & 4 & 8 \\
$<8.5$ & 0 & 3 & 7 & 10 \\
PD & & & & \\
Yes & 0 & 3 & 11 & 14 \\
No & 1 & 3 & 3 & 7 \\
LRD & & & & \\
Yes & 0 & 3 & 11 & 14 \\
No & 1 & 3 & 3 & 7 \\
Total (n=21) & 1 & 6 & 14 & 21 \\
\hline
\end{tabular}

${ }^{a}$ No significant differences were found across table IV for any of the comparisons. The total AMS score defines symptom severity as 'no/little' (17-26 points), 'mild' (27-36 points), 'moderate' (37-49 points) or 'severe' ( $\geq 50$ points) (25). Values are expressed as $n$. PD, psychiatric disorders; LRD, lifestyle-related diseases; FT, free testosterone; AMS, Ageing Males' Symptoms scale. 
A

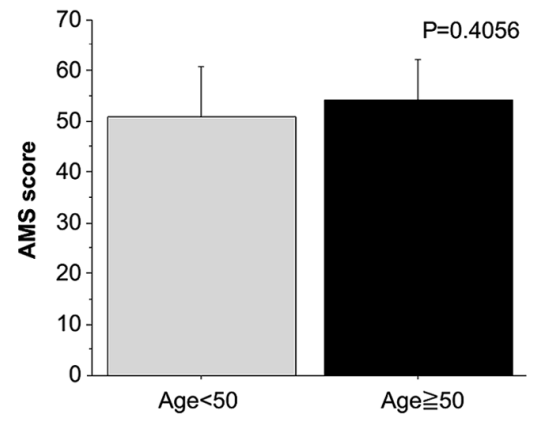

D

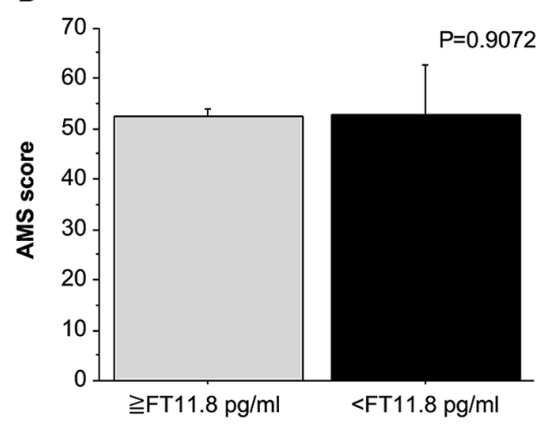

B

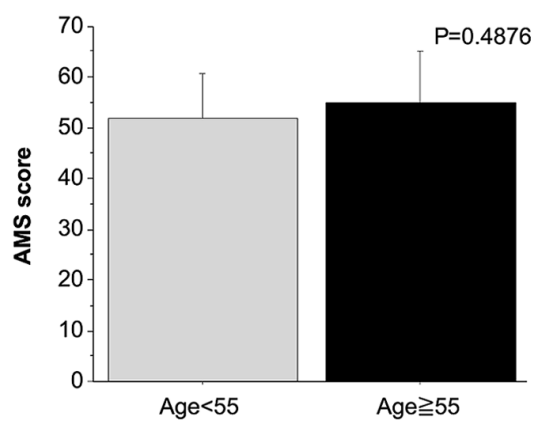

E

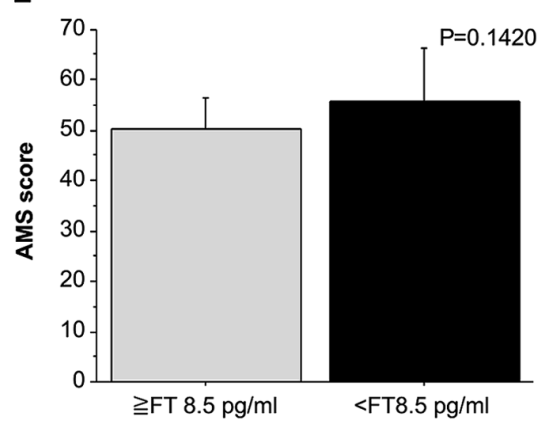

C

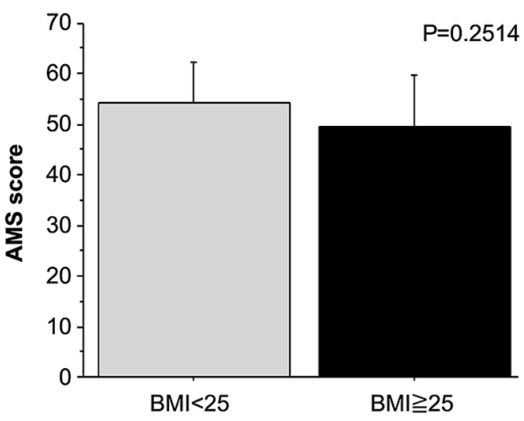

Figure 1. Comparisons of AMS scores in patients with late-onset hypogonadism syndrome stratified based on various clinical parameters. (A) Comparison of the age (cut-off, 50 years). (B) Comparison of the age (cut-off, 55 years). (C) Comparison of the BMI (cut-off, $25 \mathrm{~kg} / \mathrm{m}^{2}$ ). (D) Comparison of FT values (cut-off, $11.8 \mathrm{ng} / \mathrm{ml}$ ). (E) Comparison of FT values (cut-off, $8.5 \mathrm{ng} / \mathrm{ml}$ ). Continuous variables were presented as the mean \pm standard deviation. BMI, body mass index; FT, free testosterone; AMS, Ageing Males' Symptoms scale.

Table V. Comparison of FT between patients stratified by BMI and IPSS scores ${ }^{\mathrm{a}}$ before treatment.

\begin{tabular}{lcccr}
\hline & \multicolumn{3}{c}{ FT $(\mathrm{pg} / \mathrm{ml})$} & \\
\cline { 2 - 3 } Parameter & $<8.5$ & $8.5-11.8$ & $>11.8$ & Total \\
\hline BMI $\left(\mathrm{kg} / \mathrm{m}^{2}\right)$ & & & & \\
$<25$ & 7 & 5 & 2 & 14 \\
$\geq 25$ & 3 & 3 & 1 & 7 \\
IPSS & & & & \\
$>20$ & 3 & 1 & 0 & 4 \\
$8-20$ & 3 & 2 & 0 & 5 \\
$<8$ & 4 & 5 & 3 & 12 \\
Total (n=21) & 10 & 8 & 3 & 21 \\
\hline
\end{tabular}

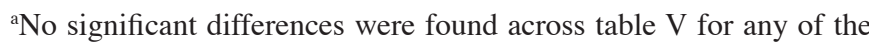
comparisons. The FT was also categorized into three groups: Low $(<8.5 \mathrm{pg} / \mathrm{ml})$, borderline zone $(\geq 8.5$ and $<11.8 \mathrm{pg} / \mathrm{ml})$ and normal $(\geq 11.8 \mathrm{pg} / \mathrm{ml})$. Values are expressed as n. FT, free testosterone; IPSS, International Prostate Scale Score; BMI, body mass index.

possible association of the FT value with each category of the AMS score (psychological, physiological and sexual function) was examined using Student's t-test (Fig. 2). There was no significant difference in the average AMS score in each category (psychological, bodily and sexual function) between patients with different FT values stratified with a cutoff at 8.5 and $11.8 \mathrm{pg} / \mathrm{ml}$.
Association of various clinical parameters with the FT value. The association between the FT value and various parameters was examined using Student's t-test (Fig. 3). There was no significant difference in the average FT value between age groups stratified with a cutoff at 50 and 55 years. There was also no significant difference in the average FT value between the normal-BMI $\left(<25 \mathrm{~kg} / \mathrm{m}^{2}\right)$ and high-BMI $\left(\geq 25 \mathrm{~kg} / \mathrm{m}^{2}\right)$ groups. Furthermore, there was no significant difference in the average FT value between different groups of patients stratified based on the IIEF-5 scores (cutoff was at 9, 16 and 21). There was also no significant difference in the average FT value between subgroups by IPSS score (no/little, moderate and severe; cutoff was at 8 and 16 , respectively).

Association of LRDs and various parameters. The association of the presence of LRDs with various parameters was examined using Student's t-test (Fig. 4). There was no significant difference in the mean values of the AMS, FT and IPSS scores between patients with and without LRDs. Of note, the mean IIEF-5 score in patients with an LRD was significantly higher than in those without an LRD, indicating that patients with an LRD may have a significantly lower sexual function $(\mathrm{P}=0.0131$; Fig. 4C).

Correlation between AMS score and various clinical parameters. The correlation between the AMS score and various clinicopathological parameters, including age, FT, BMI, PSA and IPSS score, in patients with LOH syndrome was examined using Spearman's correlation test (Fig. 5). There was no significant correlation between the AMS score and age, FT, BMI, PSA or IPSS score in patients with LOH syndrome. 
A

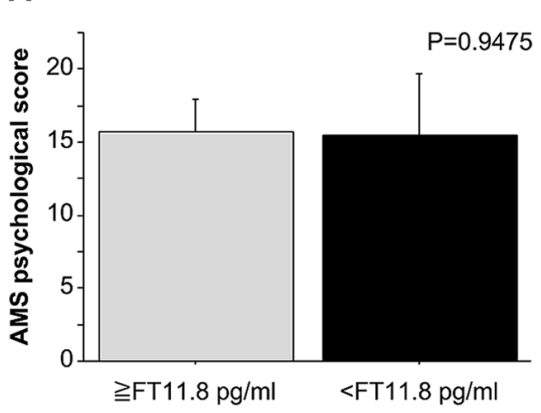

D

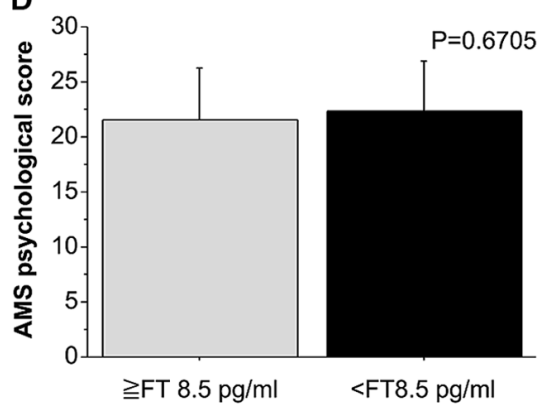

B

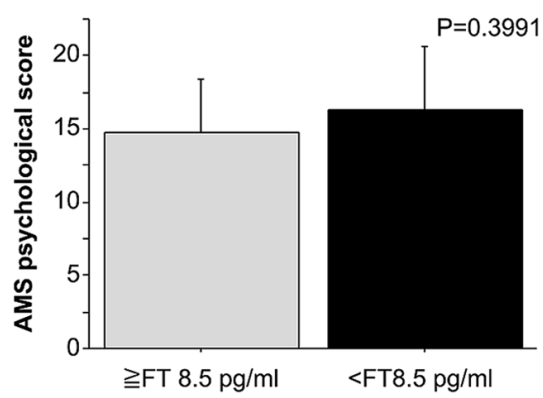

E

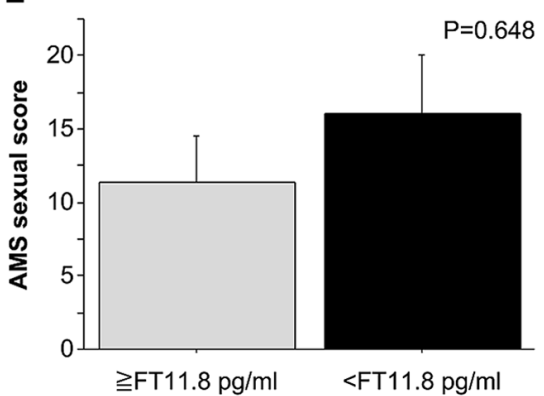

C

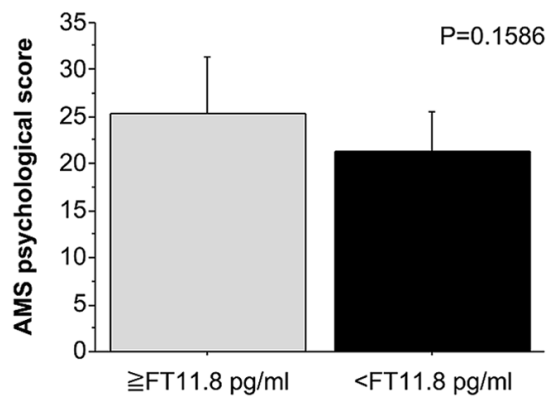

$\mathrm{F}$

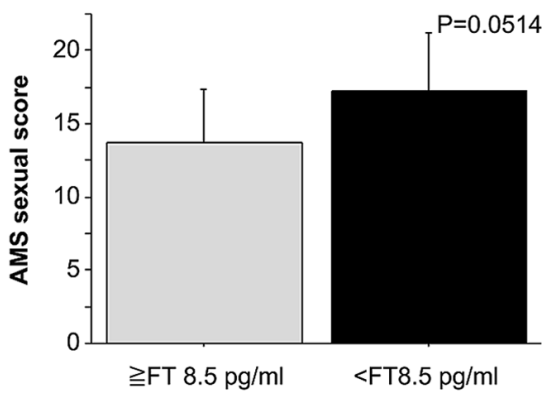

Figure 2. Comparison between each category of AMS score (psychological, physiological and sexual function) and FT value in patients with late-onset hypogonadism syndrome. (A) Comparison between AMS psychological score and FT values (cut-off, $11.8 \mathrm{ng} / \mathrm{ml}$ ). (B) Comparison between AMS psychological score and FT values (cut-off, $8.5 \mathrm{ng} / \mathrm{ml}$ ). (C) Comparison between AMS physiological score and FT values (cut-off, $11.8 \mathrm{ng} / \mathrm{ml}$ ). (D) Comparison between AMS physiological score and FT values (cut-off, $8.5 \mathrm{ng} / \mathrm{ml}$ ). (E) Comparison between AMS sexual score and FT values (cut-off, $11.8 \mathrm{ng} / \mathrm{ml}$ ). (F) Comparison between AMS sexual score and FT values (cut-off, $8.5 \mathrm{ng} / \mathrm{ml}$ ). Continuous variables were presented as the mean \pm standard deviation. FT, free testosterone; AMS, Ageing Males' Symptoms scale.
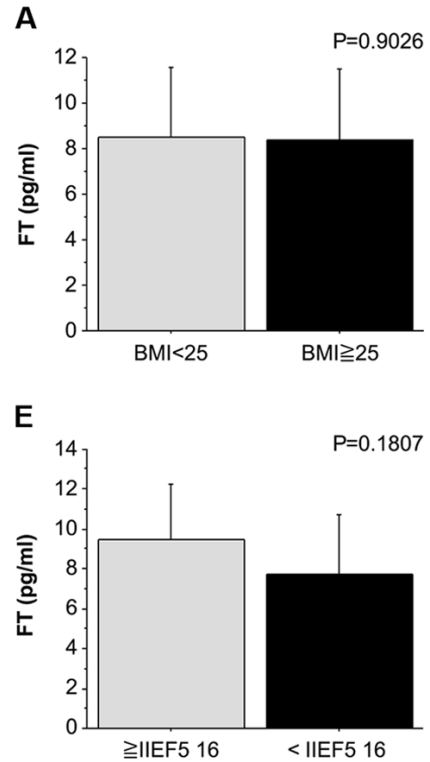

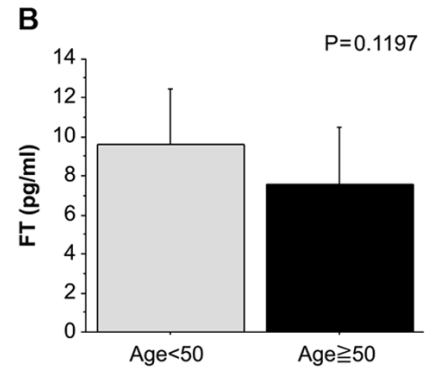

$\mathbf{F}$

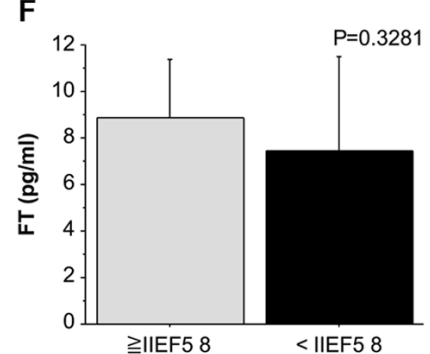

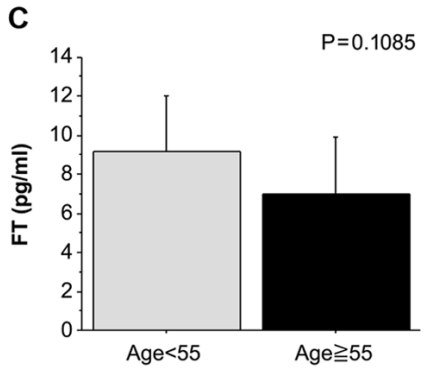

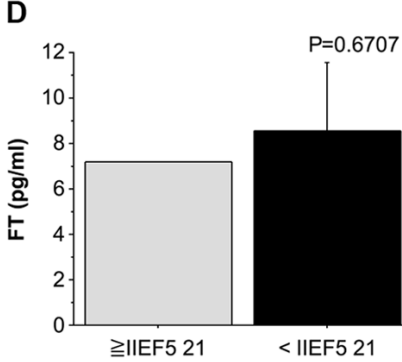

G

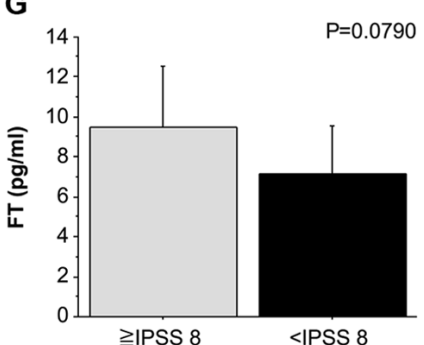

$\mathrm{H}$

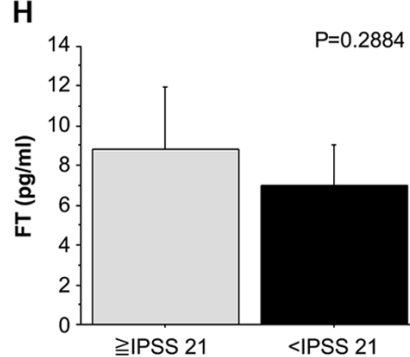

Figure 3. Comparisons of FT values in patients with late-onset hypogonadism syndrome stratified based on various clinical parameters. (A) Comparison by BMI (cut-off, $25 \mathrm{~kg} / \mathrm{m}^{2}$ ). (B) Comparison by age (cut-off, $50 \mathrm{~kg} / \mathrm{m}^{2}$ ). (C) Comparison by age (cut-off, 55 years). (D) Comparison by IIEF5 score (cut-off, 21). (E) Comparison by IIEF5 score (cut-off, 16). (F) Comparison by IIEF5 score (cut-off, 8). (G) Comparison by IPSS score (cut-off, 8). (H) Comparison by IPSS score (cut-off, 21). Continuous variables were presented as the mean \pm standard deviation. FT, free testosterone; BMI, body mass index; IEF5, International Index of Erectile Function-5; IPSS, International Prostate Scale Score.

Efficiency of combination therapy using TRT, PDE5i and herbal medicine for patients with $\mathrm{LOH}$ syndrome. The AMS scores (overall, psychological, physiological and sexual function) prior to and after each treatment were compared
(Table VI). Significant improvements in the overall AMS scores were observed after treatment in the TRT group, $\mathrm{T}$ enanthate monotherapy treatment group and $\mathrm{T}$ enanthate and PDE5i treatment group $(\mathrm{P}<0.001$; Table VIA $)$. In the 
A

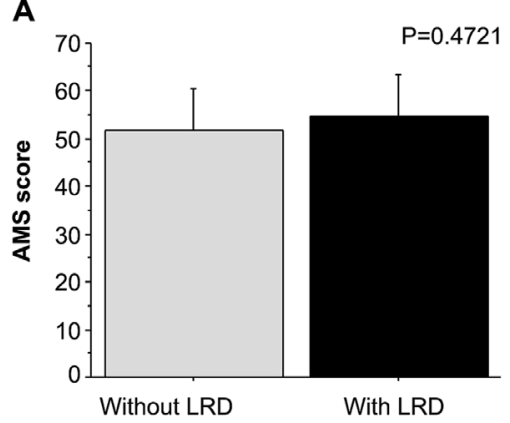

C

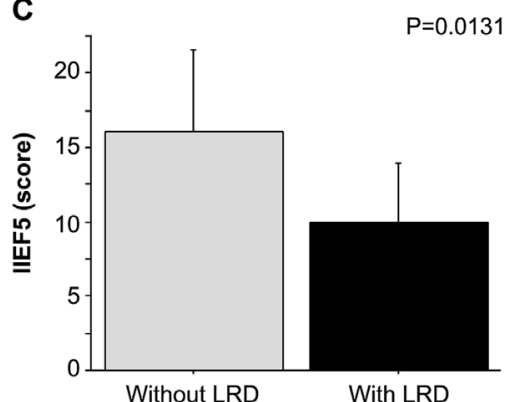

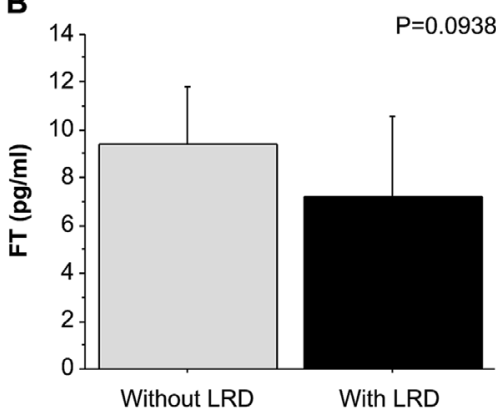

D

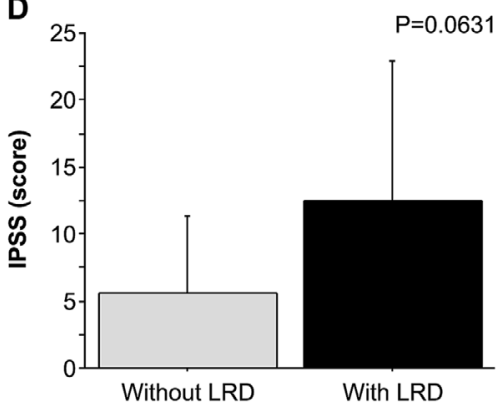

Figure 4. Comparisons of various parameters in patients with late-onset hypogonadism syndrome with and without LRD. (A) Comparison by AMS score. (B) Comparison by FT value. (C) Comparison by IIEF5 score. (D) Comparison by IPSS score. Continuous variables were presented as the mean \pm standard deviation. LRD, lifestyle-related diseases; AMS, Ageing Males' Symptoms scale; FT, free testosterone; IEF5, International Index of Erectile Function-5; IPSS, International Prostate Scale Score.

A

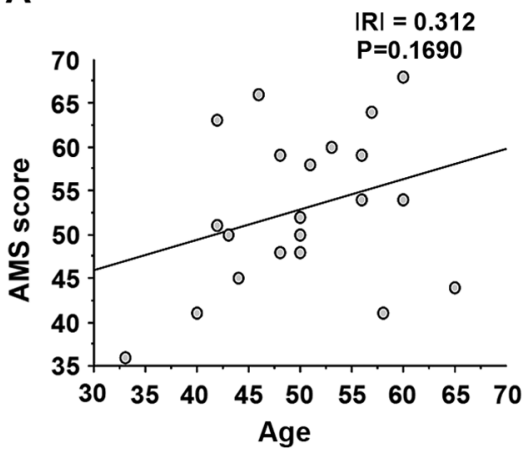

B

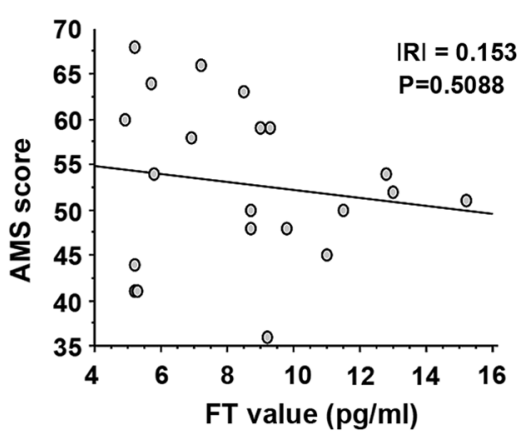

C

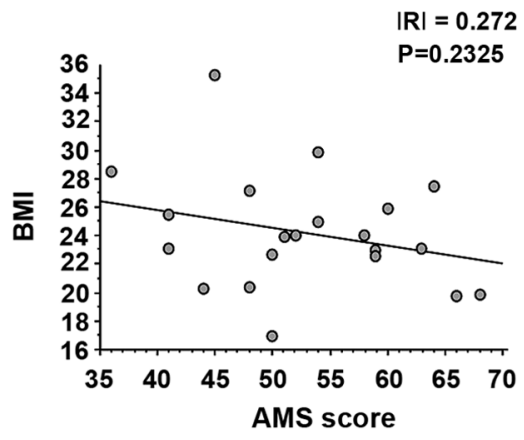

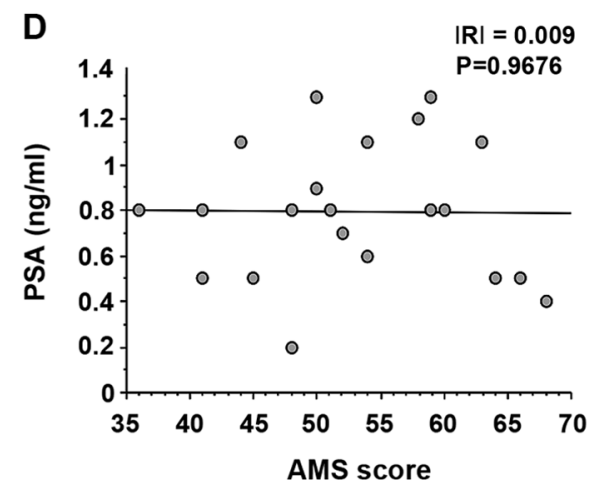

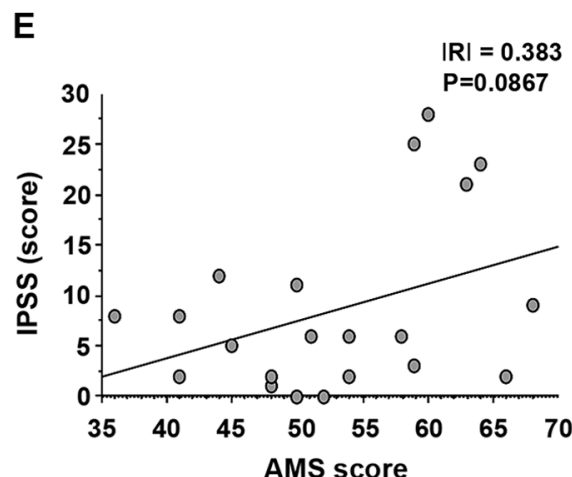

Figure 5. Correlation between AMS score and various clinical parameters in patients with late-onset hypogonadism syndrome. (A) Correlation with age (years). (B) Correlation with FT values. (C) Correlation with the BMI. (D) Correlation with PSA values. (E) Correlation by IPSS score. FT, free testosterone; AMS, Ageing Males' Symptoms scale; IPSS, International Prostate Scale Score; PSA, prostate-specific antigen.

herbal medicine group, the overall AMS scores were also slightly improved after treatment, but there was no statistical significance $(\mathrm{P}=0.144)$.
There was a significant improvement in the physiological factors of the AMS after treatment in all treatment groups $(\mathrm{P}<0.001 ;$ Table VIB). In the TRT group, including the 
Table VI. AMS scores at baseline and 12 weeks after each treatment.

A, Overall AMS score

\begin{tabular}{|c|c|c|c|}
\hline Method of treatment & AMS score prior to treatment (median) & AMS score after treatment (median) & P-value \\
\hline All $(n=21)$ & $52.9 \pm 8.8$ & $37.5 \pm 11.5$ & $<0.001$ \\
\hline TRT $(n=14)$ & $54.6 \pm 8.2$ & $38.2 \pm 10.6$ & $<0.001$ \\
\hline T enanthate monotherapy & $53.4 \pm 7.6$ & $37.0 \pm 9.9$ & $<0.001$ \\
\hline T enanthate and PDE5i & $55.3 \pm 8.1$ & $39.2 \pm 10.6$ & $<0.001$ \\
\hline Herbal medicine & $45.5 \pm 8.4$ & $34.8 \pm 16.4$ & 0.144 \\
\hline
\end{tabular}

B, AMS sub-score (physiological factors)

\begin{tabular}{|c|c|c|c|}
\hline Method of treatment & AMS score prior to treatment (median) & AMS score after treatment (median) & P-value \\
\hline All $(n=21)$ & $22.0 \pm 4.4$ & $16.0 \pm 5.5$ & $<0.001$ \\
\hline TRT $(\mathrm{n}=14)$ & $22.0 \pm 3.7$ & $15.9 \pm 4.4$ & $<0.001$ \\
\hline T enanthate monotherapy & $21.3 \pm 3.8$ & $15.1 \pm 3.8$ & $<0.001$ \\
\hline T enanthate and PDE5i & $22.0 \pm 3.8$ & $16.2 \pm 4.4$ & $<0.001$ \\
\hline Herbal medicine & $22.0 \pm 7.7$ & $16.8 \pm 9.7$ & 0.017 \\
\hline
\end{tabular}

C, AMS sub-score (psychological factors)

\begin{tabular}{|c|c|c|c|}
\hline Method of treatment & AMS score prior to treatment (median) & AMS score after treatment (median) & P-value \\
\hline All $(n=21)$ & $15.5 \pm 3.9$ & $10.3 \pm 4.0$ & $<0.001$ \\
\hline TRT $(n=14)$ & $16.5 \pm 3.1$ & $10.6 \pm 4.0$ & $<0.001$ \\
\hline T enanthate monotherapy & $16.6 \pm 2.8$ & $10.3 \pm 4.3$ & $<0.001$ \\
\hline T enanthate and PDE5i & $16.9 \pm 2.6$ & $10.9 \pm 4.0$ & $<0.001$ \\
\hline Herbal medicine & $11.3 \pm 4.6$ & $9.3 \pm 4.0$ & 0.415 \\
\hline
\end{tabular}

D, AMS sub-score (sexual function)

\begin{tabular}{|c|c|c|c|}
\hline Method of treatment & AMS score prior to treatment (median) & AMS score after treatment (median) & P-value \\
\hline All $(n=21)$ & $15.4 \pm 4.1$ & $11.1 \pm 4.1$ & $<0.001$ \\
\hline TRT $(n=14)$ & $16.1 \pm 4.0$ & $11.7 \pm 4.2$ & 0.001 \\
\hline T enanthate monotherapy & $15.4 \pm 3.8$ & $11.6 \pm 4.3$ & 0.015 \\
\hline T enanthate and PDE5i & $16.3 \pm 4.0$ & $12.1 \pm 4.1$ & 0.003 \\
\hline Herbal medicine & $12.3 \pm 3.6$ & $8.8 \pm 3.0$ & 0.322 \\
\hline
\end{tabular}

AMS, Ageing Males' Symptoms scale; PDE5i, phosphodiesterase 5 inhibitors; TRT, testosterone replacement therapy.

T enanthate monotherapy group $(\mathrm{P}<0.001)$ and the $\mathrm{T}$ enanthate + PDE5i treatment group $(\mathrm{P}<0.001)$, a significant improvement in physiological factors of AMS was achieved after treatment. In the herbal medicine group, a significant improvement in the psychological factors of AMS was also observed after treatment $(\mathrm{P}=0.017)$.

There was a significant improvement in the psychological factors of AMS after treatment in various treatment groups $(\mathrm{P}<0.001$; Table VIC). There was a significant improvement in the psychological factors of AMS after treatment in the TRT groups, including the $\mathrm{T}$ enanthate monotherapy treatment group and the
T enanthate + PDE5i treatment group, but there was no significant difference in the herbal treatment group $(\mathrm{P}=0.415)$.

There was a significant improvement in the sexual functional factors of AMS after treatment in several treatment groups $(\mathrm{P}<0.001$; Table VID). In the TRT groups, including the $\mathrm{T}$ enanthate monotherapy group and $\mathrm{T}$ enanthate + PDE5i treatment group, the sexual function factors of AMS were significantly improved after treatment $(\mathrm{P}<0.001)$. In the herbal medicine group, the AMS sexual functional factors were also slightly improved after treatment, but there was no significant difference $(\mathrm{P}=0.322)$. 
A

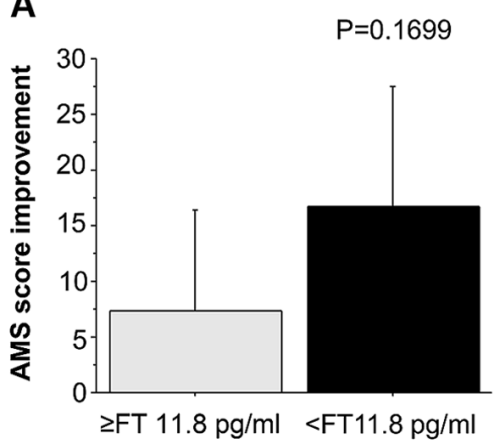

B

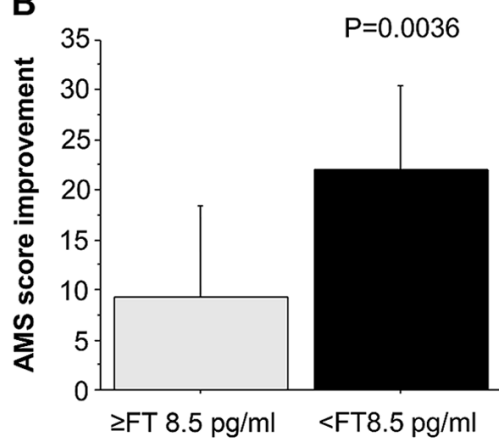

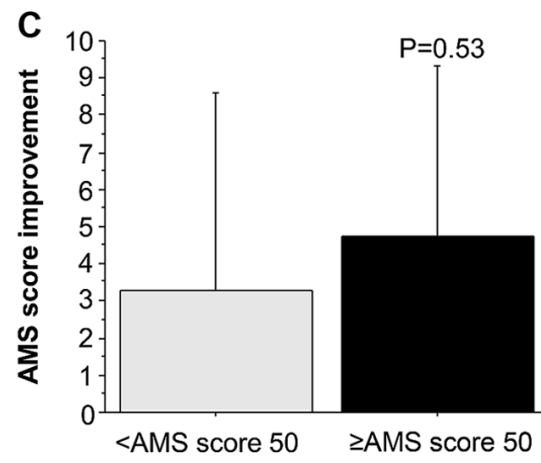

Figure 6. Comparison of improvement in AMS score after treatment vs. baseline in patients with late-onset hypogonadism syndrome stratified by their baseline AMS or FT score. (A) Comparison of AMS score improvement in patients stratified by their FT value prior to treatment (cut-off, 8.5 ng/ml). (B) Comparison of AMS score improvement in patients stratified by their FT value prior to treatment (cut-off, $11.8 \mathrm{ng} / \mathrm{ml}$ ). (C) AMS score improvement in patients stratified by their AMS score prior to treatment (cut-off, 50). Continuous variables were presented as the mean \pm standard deviation. FT, free testosterone; AMS, Ageing Males' Symptoms scale.

A

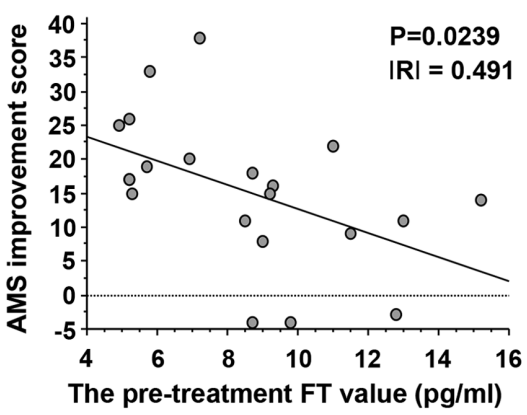

C

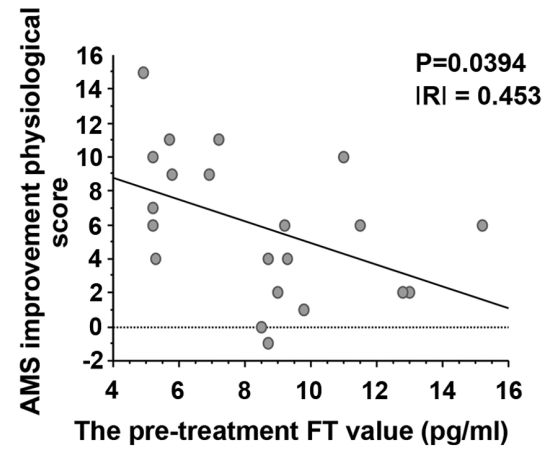

B

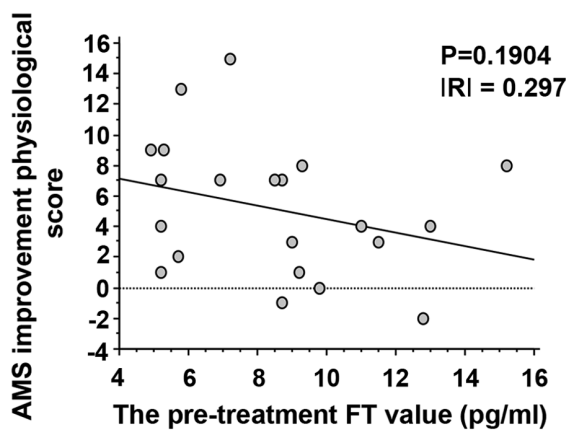

D

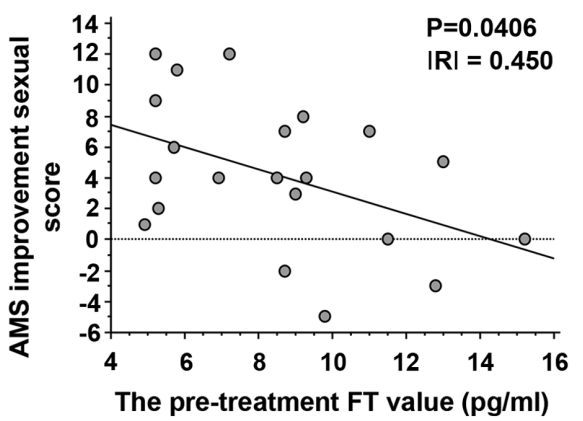

Figure 7. Correlation between improvement in AMS score (all, psychological factors, physiological factors and sexual factors) after treatment and FT value prior to treatment in patients with late-onset hypogonadism syndrome. (A) Correlation between the improvement in overall AMS score and pre-treatment FT value. (B) Correlation between the improvement in AMS psychological score and the pre-treatment FT value. (C) Correlation between the improvement in AMS physiological score and the pre-treatment FT value. (D) Correlation between the improvement in AMS sexual score and the pre-treatment FT value. FT, free testosterone; AMS, Ageing Males' Symptoms scale.

Associations among AMS score improvement and FT value prior to treatment or AMS score prior to treatment. The association of the AMS score improvement with the FT value prior to treatment or the AMS score prior to treatment was examined using Student's t-test (Fig. 6). The average difference in the AMS score prior to vs. after treatment, defined as the AMS score improvement via treatment, was compared between patients with different pre-treatment FT values stratified with cutoff values of 8.5 and $11.8 \mathrm{pg} / \mathrm{ml}$. The results indicated that a lower pre-treatment FT value was associated with a greater improvement in AMS. Of note, the improvement in AMS was significantly higher in the group with an FT value of $<8.5 \mathrm{pg} / \mathrm{ml}$ prior to treatment as compared with that in the group with FT $\geq 8.5 \mathrm{pg} / \mathrm{ml}$ ( $\mathrm{P}=0.0036$; Fig. 6B).

The cohort was then divided based on the AMS score prior to treatment with a cutoff at 50 points, and the AMS score improvements via treatment were compared between these two subgroups. A higher pre-treatment AMS score was associated with a greater improvement in AMS score after treatment; however, this difference was not significant. It may be concluded that patients with a lower FT value and 
Table VII. Clinical screening factors were not significantly changed after all treatments compared with the baseline value.

\begin{tabular}{lccc}
\hline Parameter & Prior to treatment (median) & After treatment (median) & P-value \\
\hline LH & $2.8 \pm 1.5$ & $1.6 \pm 1.8$ & 0.007 \\
T-cho & $212.0 \pm 47.0$ & $207.1 \pm 33.2$ & 0.439 \\
Hb & $15.3 \pm 1.1$ & $15.4 \pm 1.1$ & 0.668 \\
FT & $8.5 \pm 3.0$ & $9.6 \pm 4.0$ & 0.368 \\
IIEF5 score & $13.4 \pm 5.7$ & $16.0 \pm 5.1$ & 0.010 \\
IPSS score & $8.6 \pm 8.6$ & $6.4 \pm 5.9$ & 0.072 \\
\hline
\end{tabular}

FT, free testosterone; Hb, hemoglobin; LH, luteinizing hormone; T-cho, total cholesterol; IEF5, International Index of Erectile Function-5; IPSS, International Prostate Scale Score.

a higher AMS score prior to treatment may exhibit a greater AMS score improvement following treatment. In particular, the patient group with a pre-treatment FT value of $<8.5 \mathrm{pg} / \mathrm{ml}$ presented with a significantly higher therapeutic effect.

Correlation between improvement in AMS score (overall, psychological, physiological and sexual functioning) and FT value prior to treatment. Upon examination using Spearman's correlation test, the correlation between the improvement in the AMS score and the pre-treatment FT value exhibited a significant negative correlation $(\mathrm{P}=0.0239$; Fig. 7A). In other words, patients with a lower FT value prior to treatment had a greater improvement in AMS score after the treatment.

Examination of the correlation between the improvement in the psychological AMS score with the FT value prior to treatment revealed no significant correlation ( $\mathrm{P}=0.1904$; Fig. 7B). However, the improvement of the AMS score of physiological and sexual functioning and the FT value prior to treatment indicated a significant negative correlation $(\mathrm{P}=0.0394$ and $\mathrm{P}=0.0406$; Fig. 7C and D, respectively). In conclusion, patients with a lower FT value prior to treatment had significantly improved overall AMS scores, as well as AMS scored of physical and sexual function.

Examination of changes in each clinical factor after vs. prior to treatment. Combining all treatments, a significant decrease in serum LH after treatment was observed $(\mathrm{P}=0.007$; Table VII). Furthermore, slight but insignificant increases in FT levels, as well as an insignificant decrease in the serum T-Cho were detected after treatment. A significant increase in the IIEF-5 score was observed after treatment $(\mathrm{P}=0.01$; Table VII), demonstrating that combination therapy using TRT, PDE5i and herbal medicine may contribute to the treatment of sexual dysfunction. Furthermore, there was a decrease in the IPSS score after treatment, but it was not significant.

\section{Discussion}

In the present study, the treatments were selected based on the clinical background and initial therapeutic effects in 21 males treated for $\mathrm{LOH}$ syndrome as outpatients were evaluated and good results regarding improvement of the symptoms based on the AMS score were obtained in each treatment group.
The association between sex hormones and urological diseases has been reported previously (31). In recent years, it has become widely recognized that menopausal-like symptoms may occur in middle-aged and elderly males, as well as in females, due to decreased androgen production. The term $\mathrm{LOH}$ syndrome is now being used to describe this condition and it is defined as a 'syndrome by androgen decrease according to age that may result in multi-organ dysfunction and decrease in QOL' (1). Testosterone and associated hormonal changes due to ageing are more clearly reduced by ageing for FT compared to TT. SHBG increases the decrease in FT and albumin-bound testosterone. Adrenal androgens are also on the decline with increasing age (2,3). Liu et al (32) reported that genetic variation among individuals exists in the number of CAG repeats in the androgen receptor and affects the therapeutic effect of genetic polymorphisms, and that the number of repeats and androgenic activity are inversely related. They also indicated that patients with serum TT levels of $340 \mathrm{ng} / \mathrm{dl}$ or higher tend to develop $\mathrm{LOH}$ symptoms if they have CAG repeat lengths of $\geq 25$.

In the present study, patients with FT of $<8.5 \mathrm{pg} / \mathrm{ml}$ at the first visit exhibited a significantly greater improvement in their AMS score after treatment as compared with those with an FT of $\geq 8.5 \mathrm{pg} / \mathrm{ml}$. In addition, there was a negative correlation between AMS score improvement following treatment and FT levels at the first visit. This suggests that, in patients with low FT, the symptoms of LOH syndrome may be improved by aggressive intervention using combination therapy with TRT, herbal medicine and PDE5i. Although various physical, psychological or sexual dysfunction symptoms may occur in $\mathrm{LOH}$ syndrome, TRT is considered the first treatment, as androgen deficiency is the essence of the condition (5). However, it has also been indicated that an increase in the blood testosterone concentration due to testosterone administration is caused by aging (33).

In the present study, a significant increase in the IIEF-5 score after treatment was observed, suggesting that combination therapy using TRT, herbal medicine and PDE5i may be effective as a single treatment for sexual dysfunction. Sexual decline is an important clinical manifestation of $\mathrm{LOH}$ syndrome. In particular, when the three items of low sexual desire, i.e., decreased nocturnal and morning erections and $\mathrm{ED}$, appear together, LOH syndrome is more strongly indicated (34). As for the association between testosterone and 
erectile ability, a Japanese study has reported that IIEF-5 increases when testosterone increases (35); this trend was also indicated in a study from the US (36). In the present study, lower pre-treatment FT levels were associated with a greater increase in total AMS score for physical and sexual function following treatment. Various factors affecting the sexual function of testosterone have been reported and the basic research results expected to also be observed in clinical practice are as follows: i) Nitric oxide synthase activity stimulation as a physiological effect; ii) maintenance of penile structure and function as a developmental effect; iii) development, maintenance, function and plasticity of erectile nerve and pelvic plexus as neurological effects; and iv) improvement in resistance of PDE5i for ED as an anti-ageing effect $(2,3)$.

Symptoms resulting from changes in testosterone with age are defined as $\mathrm{LOH}$ syndrome. However, a decrease in testosterone from various causes may be associated with the development of symptoms as well as ageing. A study reported that the rate of testosterone changes is a factor predicting the onset of symptoms of LOH syndrome (37). In addition, the threshold of symptom manifestation due to the decrease in testosterone varies depending on the organ it affects (38).

Decreased serum testosterone may be associated with specific symptoms and metabolic risks in males (10). In the present study, no significant correlation between PSA and testosterone was observed. PSA, a tumor marker for prostate cancer, is used as an indicator for prostate cancer diagnosis and treatment (39). Rastrelli et al (40) reported that PSA was a marker of the testosterone concentration and that it may represent a novel indicator for confirming hypogonadism. They also stated that determining PSA levels may provide insight not only regarding the circulating levels of TT but also its active fractions.

In the present study, the efficiency of a combination treatment using several drugs that have been reported to be efficacious in patients with LOH syndrome, i.e., T enanthate, testosterone ointment, PDE5i and herbal medicines, was evaluated. The effect of each treatment on $\mathrm{LOH}$ syndrome has been previously reported, primarily that of $\mathrm{T}$ enanthate. Snyder et al (41) reported on a randomized controlled trial (RCT) that examined the effectiveness of TRT for the most common complaints among the middle-aged and elderly. Their results indicated that the effects on sexual function factors, including sexual activity, libido and erectile ability, physical function factors, including walking distance and vitality, and psychological function, including depression symptoms, improved in the TRT group. The present report had a patient cohort recruited based on a tight selection criteria $(n=790)$, testosterone was controlled within the physiological range after TRT (41).

In the present study, there were no adverse events requiring treatment interruption in any group during the drug administration period. To date, no RCT with sufficient power to adequately assess the impact of TRT on cardiovascular events and death has been performed. A previous retrospective study including almost 4,000 cases suggested that TRT does not increase the risk of cardiovascular events (42).

It is unlikely that prostate cancer is caused by TRT. In a meta-analysis of clinical trials on the use of TRT, the frequency prostate cancer as an adverse event detected in the placebo group and hormone replacement group was not significantly different, but rather in patients with lower testosterone levels, the rate of aggressive prostate cancer was relatively high (43).

Although androgen is a steroid hormone that is thought to affect not only male reproductive organs, but also numerous other organs, tissues, biological functions and even behaviors, the mechanisms of action of androgens have remained to be fully elucidated. Conventional side effects that should be considered when administering TRT include cardiovascular disease, abnormal lipid metabolism, polycythemia, fluid retention, prostatic hypertrophy, prostate cancer, hepatotoxicity, SAS, gynecomastia, acne, testis atrophy, infertility, and behavioral and mood changes $(44,45)$. In the present study, the significant decrease in the plasma levels of LH following testosterone treatment may have been due to suppression of $\mathrm{LH}$, the upstream hormone of testosterone (46). This is important for clinicians to note, since it may lead to testicular atrophy and requires monitoring, including blood tests during the course of treatment for $\mathrm{LOH}$ syndrome.

The present study covered initial treatment for $\mathrm{LOH}$, over three months from the start of treatment. In patients who received medical intervention for $\mathrm{LOH}$ syndrome, the physical and sexual function, as well as total AMS scores, improved after treatment for three months. There was also a significant improvement in the IIEF-5 score for sexual function factors following treatment. Tsujimura et al (47) administered TRT for patients with $\mathrm{LOH}$ for 7.3 months on average. Their analyses prior to treatment, after treatment and three months after treatment indicated that, at three months after treatment, testosterone had returned to pre-treatment levels, but the total AMS and physical and psychological factor scores were significantly improved by the treatment and were maintained at three months after the end of treatment. Lifelong TRT is not always required for patients with improved symptoms (47). From this point of view, it appears to be important to improve symptoms via initial treatment. Although the present study was limited to an evaluation of the initial three months of treatment, it is worthwhile due the importance of the initial treatment.

There is no universally agreed threshold for 'normal' serum testosterone levels. In addition, there are no generally accepted lower limits of normal TT. LOH syndrome comprises non-specific, indefinite complaints and the symptoms are particularly similar to those of peripheral depression. The target serum testosterone levels for TRT are not absolutely diagnostic. Careful differentiation of whether a symptom is due to LOH syndrome is important for a more accurate diagnosis. To increase the accuracy of LOH syndrome diagnosis, decreased vigor, decreased energy and motivation, fatigue, depressive mood and sleep disturbances may also be associated with LOH syndrome, and physical symptoms may appear as obesity and increased blood levels of cholesterol. The association between symptoms and testosterone levels is not clear in numerous cases and inter-individual differences in the appearance of these symptoms must be taken into account. Furthermore, the diagnosis should be made by comprehensively considering the decrease in serum testosterone levels, the aforementioned symptoms and the results of a physical examination (48). 
According to Japanese guidelines, hormone replacement therapy is not performed in patients with FT of $\geq 11.8 \mathrm{pg} / \mathrm{ml}$ and treatments should be considered depending on the symptoms (5). In the present study, herbal medicine treatment was also effective. The herbal medicines were not as potent as the TRT treatments and no significant change was achieved for numerous parameters. However, the herbal medicines were instead given to the patients with less severe $\mathrm{LOH}$ at baseline and with higher FT, so that the magnitude of the changes required to reach a near-normal state were not as high. In particular, there was a significant improvement in the scores related to physical symptoms of AMS. In herbal medicine, Hochuekkito has been reported to increase testosterone levels; Saikouka Ryubon-Oyakuto has no effect on testosterone levels but has been reported to improve the symptoms of LOH via cytokines $(19,49)$.

In relation to Mets, including LRDs and urological diseases, dysuria and urolithiasis are well known, but other associations of Mets and LOH syndrome have also been reported $(50,51)$. Decreased testosterone levels are a significant risk factor for type 2 diabetes and Mets $(52,53)$. RCTs have gradually demonstrated the effects of TRT on metabolic factors. A recent meta-analysis of the effects TRT on metabolic factors in a middle-aged group of patients in their 50s, based on multiple RCTs, indicated that it should improve insulin sensitivity and hyperlipidemia in addition to decreasing abdominal circumference (54).

The limitations of the present study include the small number of cases, the retrospective study design and the short observation period. It is difficult to draw an affirmative conclusion based on this number of patients. Therefore, the results of the present study only suggest certain trends. Future tasks are to acquire cases and follow their long-term progress, as well as to determine the effectiveness of each treatment method, side effects and drug combination effects. In addition, drug treatment and examination of the effects of nutritional therapy on LOH syndrome are necessary.

In conclusion, among the outpatients with $\mathrm{LOH}$ syndrome who presented at our hospital, improved AMS scores were observed in numerous cases following treatment intervention using combination or single therapy with TRT, herbal medicine and PDE5i, and the outcomes were favorable.

From these results, it was indicated that lower serum FT levels prior to treatment were associated with a significantly greater improvement in AMS score after treatment. In particular, the physical and sexual function factors and AMS scores after treatment were significantly more improved in the group with FT $<8.5 \mathrm{pg} / \mathrm{ml}$ at the first visit. These results suggest that patients with LOH syndrome with low FT are likely to experience symptom improvement by treatment intervention. There was also a significant increase in the IIEF-5 score after treatment. This suggests that combination therapy using TRT, herbal medicine and PDE5i may be effective as a single treatment for sexual dysfunction.

In addition to TRT, numerous treatments have been reported for $\mathrm{LOH}$ syndrome, and these treatments achieved good results in the present study. Thus, it is required to evaluate the symptoms of each patient with LOH syndrome to judge whether they require treatment intervention and determine the appropriate treatment method.

\section{Acknowledgements}

Not applicable.

\section{Funding}

No funding was received.

\section{Availability of data and materials}

The datasets used and/or analyzed during the current study are available from the corresponding author on reasonable request.

\section{Authors' contributions}

HT designed the study, contributed to analysis and interpretation of data. HT and HO were involved in the treatment of actual patients at the hospital, made a contribution to the acquisition of data for this study and confirmed the authenticity of all the raw data. Both authors approved the final version of the manuscript, and agree to be accountable for all aspects of the work in ensuring that questions related to the accuracy or integrity of any part of the work are appropriately investigated and resolved.

\section{Ethics approval and consent to participate}

All procedures of the present study were approved by the Ethical Committee of Kyoeikai Okubo Hospital (Ibaraki, Japan). All patients provided written informed consent to participate in the present study.

\section{Patient consent for publication}

Not applicable.

\section{Competing interests}

The authors declare that they have no competing interests.

\section{References}

1. Nieschlag E, Swerdloff R, Behre HM, Gooren LJ, Kaufman JM, Legros JJ, Lunenfeld B, Morley JE, Schulman C, Wang C, et al: Investigation, treatment, and monitoring of late-onset hypogonadism in males: ISA, ISSAM, and EAU recommendations. J Androl 27: 135-137, 2006.

2. Feldman HA, Longcope C, Derby CA, Johannes CB, Araujo AB, Coviello AD, Bremner WJ and McKinlay JB: Age trends in the level of serum testosterone and other hormones in middle-aged men: Longitudinal results from the Massachusetts male aging study. J Clin Endocrinol Metab 87: 589-598, 2002.

3. Wu FC, Tajar A, Pye SR, Silman AJ, Finn JD, O'Neill TW, Bartfai G, Casanueva F, Forti G, Giwercman A, et al: Hypothalamic-pituitary-testicular axis disruptions in older men are differentially linked to age and modi able risk factors: The European Male Aging Study. J Clin Endocrinol Metab 93: 2737-2745, 2008.

4. Wang C, Nieschlag E, Swerdloff R, Behre HM, Hellstrom WJ, Gooren LJ, Kaufman JM, Legros JJ, Lunenfeld B, Morales A, et al: Investigation, treatment and monitoring of late-onset hypogonadism in males: ISA, ISSAM, EAU, EAA and ASA recommendations. Eur J Endocrinol 159: 507-514, 2008.

5. Japanese Urological Association/Japanese Men's Health Medicine Association: LOH symptom group - Aging Male Hypogonadism Syndrome Medical Guidance. Jihou, Tokyo, 4-7, 2007. 
6. Okamura K, Ando F and Shimokata H: Serum total and free testosterone level of Japanese men: A population-based study. Int J Urol 12: 810-814, 2005.

7. Iwamoto T, Yanase T, Horie H, Namiki M and Okuyama A: Late-onset hypogonadism ( $\mathrm{LOH}$ ) and androgens: Validity of the measurement of free testosterone levels in the diagnostic criteria in Japan. Int J Urol 16: 168-174, 2009.

8. Miwa Y, Kaneda T and Yokoyama O: Correlation between the Aging Males' symptoms Scale and sex steroids, gonadotropins, dehydroepiandrosterone sulfate, and growth hormone levels in ambulatory men. J Sex Med 3: 723-726, 2006.

9. Nieschlag E: Testosterone treatment comes of age: New options for hypogonadal men. Clin Endocrinol (Oxf) 65: 275-281, 2006.

10. Wang C, Swerdloff RS, Iranmanesh A, Dobs A, Snyder PJ, Cunningham G, Matsumoto AM, Weber T and Berman N Testosterone Gel Study Group: Transdermal testosteron gel improves sexual function, mood, muscle strength, body composition parameters in hypogonadal men. J Clin Endocrinol Metab 85: 2839-2853, 2000.

11. Tenover JS: Effects of testosterone supplementation in the aging male. J Clin Endocrinol Metab 75: 1092-1098, 1992.

12. Buvat J, Maggi M, Gooren L, Guay AT, Kaufman J, Morgentaler A, Schulman C, Tan HM, Torres LO, Yassin A and Zitzmann M: Endocrine aspects of male sexual dysfunctions. J Sex Med 7: 1627-1656, 2010 .

13. Ide H, Yasuda M, Nishio K, Saito K, Isotani S, Kamiyama Y, Muto $S$ and Horie S: Development of a nomogram for predicting high-grade prostate cancer on biopsy: The significance of serum testosterone levels. Anticancer Res 28C: 2487-2492, 2008.

14. Bagatell CJ and Bremner WJ: Androgens in men: Uses and abuses. N Engl J Med 334: 707-714, 1996.

15. Coates JM and Herbert J: Endogenous steroids and financial risk taking on a London trading floor. Proc Natl Acad Sci USA 105: 6167-6172, 2008

16. Muller M, Grobbee DE, den Tonkelaar I, Lamberts SW and van der Schouw YT: Endogenous sex hormones and metabolic syndrome in aging men. J Clin Endocrinol Metab 90: 2618-2623, 2005 .

17. Bhasin S, Cunningham GR, Hayes FJ, Matsumoto AM, Snyder PJ, Swerdloff RS and Montori VM: Testosterone therapy in adult men with androgen deficiency syndromes: An endocrine society clinical practice guideline. J Clin Endocrinol Metab 91: 1995-2010, 2006

18. Srinivas-Shankar U, Roberts SA, Connolly MJ, O'Connell MD, Adams JE, Oldham JA and Wu FC: Effects of testosterone on muscle strength, physical function, body composition, and quality of life in intermediate-frail and frail elderly men: A randomized, double-blind, placebo-controlled study. J Clin Endocrinol Metab 95: 639-650, 2010.

19. Amano T, Imao T and Takemae K: Clinical efficacy of Japanese traditional herbal medicine (Kampo) in patients with late-onset hypogonadism. Aging Male 13: 166-173, 2010.

20. Tsujimura A, Takada S, Matsuoka Y, Nakayama J, Takao T, Miyagawa Y, Nonomura N and Okuyama A: Clinical trial of treatment with saikokaryukotsuboreito for eugonadal patients with late-inset hypogonadism-related symptoms. Aging Male 11: 95-99, 2008

21. Takeuchi H, Taoka R, Mmeje CO, Jinesh GG, Safe S and Kamat AM: CDODA-Me decreases specificity protein transcription factors and induces apoptosis in bladder cancer cells through induction of reactive oxygen species. Urol Oncol 34: 337.e11-8, 2016.

22. Yasuda M, Ide H, Horie S, Yoshii T, Nishio K, Saito K, Isotani S, Kamiyama Y, Muto S and Horie S: Salivary 8-OHdG: A useful biomarker for predicting severe ED and hypogonadism. J Sex Med 5: 1482-1491, 2008.

23. Podlasek CA, Mulhall J, Davies K, Wingard CJ, Hannan JL, Bivalacqua TJ, Musicki B, Khera M, González-Cadavid NF and Burnett AL II: Translational perspective on the role of testosterone in sexual function and dysfunction. J Sex Med 13: $1183-1198,2016$

24. Amano T, Iwamoto T, Sato Y, Imao T and Earle C: The efficacy and safety of short-acting testosterone ointment (Glowmin) for late-onset hypogonadism in accordance with testosterone circadian rhythm. Aging Male 21: 170-175, 2018.

25. Heinemann LA, Zimmermann T, Vermeulen A, Thiel $\mathrm{C}$ and Hummel W: A new 'aging males' symptoms' (AMS) rating scale. Aging Male 2: 105-114, 1999.
26. Barry MJ, Fowler FJ Jr, O'Leary MP, Bruskewitz RC, Holtgrewe HL, Mebust WK and Cockett AT: The American urological association symptom index for benign prostatic hyperplasia. The measurement committee of the American urological association. J Urol 148: 1549-1557; discussion 1564, 1992.

27. Rosen RC, Cappelleri JC, Smith MD, Lipsky J and Peña BM: Development and evaluation of an abridged, 5-item version of the International index of erectile function (IIEF-5) as a diagnostic tool for erectile dysfunction. Int J Impot Res 11: 319-326, 1999.

28. Frankenfield DC, Rowe WA, Cooney RN, Smith JS and Becker D Limits of body mass index to detect obesity and predict body composition. Nutrition 17: 26-30, 2001.

29. WHO Expert Consultation: Appropriate body-mass index for Asian populations and its implications for policy and intervention strategies. Lancet 363: 157-163, 2004

30. Sato Y, Tanda H, Kato S, Onishi S, Nakajima H, Nanbu A, Nitta T, Koroku M, Akagashi K and Hanzawa T: Prevalence of major depressive disorder in self-referred patients in a late onset hypogonadism clinic. Int J Impot Res 19: 407-410, 2007.

31. Takeuchi H, Mmeje CO, Jinesh GG, Taoka R and Kamat AM: Sequential gemcitabine and tamoxifen treatment enhances apoptosis and blocks transformation in bladder cancer cells. Oncol Rep 34: 2738-2744, 2015

32. Liu CC, Lee YC, Wang CJ, Yeh HC, Li WM, Wu WJ, Huang CN, Bao BY, Huang $\mathrm{CH}$ and Huang SP: The impact of androgen receptor CAG repeat polymorphism on andropausal symptoms in different serum testosterone levels. J Sex Med 9: 2429-2437, 2012.

33. Coviello AD, Lakshman K, Mazer NA and Bhasin S: Differences in the apparent metabolic clearance rate of testosterone in young and older men with gonadotropin suppression receiving graded doses of testosterone. J Clin Endocrinol Metab 91: 4669-4675, 2006.

34. Wu FC, Tajar A, Beynon JM, Pye SR, Silman AJ, Finn JD, O'Neill TW, Bartfai G, Casanueva FF, Forti G, et al: Identification of late-onset hypogonadism in middle-aged and elderly men. N Engl J Med 363: 123-135, 2010.

35. Tsujimura A, Matsumiya K, Matsuoka Y, Takahashi T, Koga M, Iwasa A, Takeyama M and Okuyama A: Bioavailable testosterone with age and erectile dysfunction. J Urol 170: 2345-2347, 2003.

36. Cunningham GR, Stephens-Shields AJ, Rosen RC, Wang C, Ellenberg SS, Matsumoto AM, Bhasin S, Molitch ME, Farrar JT, Cella D, et al: Association of sex hormones with sexual function, vitality, and physical function of symptomatic older men with low testosterone levels at baseline in the testosterone trials. J Clin Endocrinol Metab 100: 1146-1155, 2015.

37. Holm AC, Fredrikson MG, Theodorsson E, Palmefors LG, Karlsson PS, Joborn C and Hammar ML: Change in testosterone concentrations over time is a better predictor than the actual concentrations for symptoms of late onset hypogonadism. Aging Male 14: 249-256, 2011.

38. Zitzmann M, Faber S and Nieschlag E: Association of specific symptoms and metabolic risks with serum testosterone in older men. J Clin Endocrinol Metab 91: 4335-4343, 2006.

39. Takeuchi H, Ohori M and Tachibana M: Clinical significance of the prostate-specific antigen doubling time prior to and following radical prostatectomy to predict the outcome of prostate cancer. Mol Clin Oncol 6: 249-254, 2017.

40. Rastrelli G, Corona G, Vignozzi L, Maseroli E, Silverii A, Monami M, Mannucci E, Forti G and Maggi M: Serum PSA as a predictor of testosterone deficiency. J Sex Med 10: 2518-2528, 2013.

41. Snyder PJ, Bhasin S, Cunningham GR, Matsumoto AM, Stephens-Shields AJ, Cauley JA, Gill TM, Barrett-Connor E, Swerdloff RS, Wang C, et al: Effects of testosterone treatment in older men. N Engl J Med 374: 611-624, 2016.

42. Anderson JL, May HT, Lappé DL, Bair T, Le V, Carlquist JF and Muhlestein JB: Impact of testosterone replacement therapy on myocardial infarction, stroke, and death in men with low testosterone concentrations in an integrated health care system. Am J Cardiol 117: 794-799, 2016.

43. Feneley MR and Carruthers M: Is testosterone treatment good for the prostate? Study of safety during long-term treatment. J Sex Med 9: 2138-2149, 2012.

44. Morales A and Lunenfeld B; International Society for the Study of the Aging Male: Investigation, treatment and monitoring of late-onset hypogonadism in males. Official recommendations of ISSAM. International Society for the Study of the Aging Male. Aging Male 5: 74-86, 2002. 
45. Rhoden EL and Morgentaler A: Risks of testosterone-replacement therapy and recommendations for monitoring. N Engl J Med 350: 482-492, 2004.

46. Gregory SJ and Kaiser UB: Regulation of gonadotropins by inhibin and activin. Semin Reprod Med 22: 253-267, 2004.

47. Tsujimura A, Takada S, Matsuoka Y, Hirai T, Takao T, Miyagawa $\mathrm{Y}$, Nonomura $\mathrm{N}$ and Okuyama A: Is discontinuation of hormone replacement therapy possible for patients with late-onset hypogonadism? Int J Urol 15: 625-629, 2008.

48. Khera M, Adaikan G, Buvat J, Carrier S, El-Meliegy A, Hatzimouratidis K, McCullough A, Morgentaler A, Torres LO and Salonia A: Diagnosis and treatment of testosterone deficiency: Recommendations from the Fourth International consultation for sexual medicine (ICSM 2015). J Sex Med 13: 1787-1804, 2016.

49. Tsujimura A, Miyagawa Y, Okuda H, Yamamoto K, Fukuhara S, Nakayama J, Takao T, Nonomura N and Okuyama A: Change in cytokine levels after administration of saikokaryuukotsuboreito or testosterone in patients with symptoms of late-onset hypogonadism. Aging Male 14: 76-81, 2011.

50. Kupelian V, McVary KT, Kaplan SA, Hall SA, Link CL, Aiyer LP, Mollon P, Tamimi N, Rosen RC and McKinlay JB: Association of lower urinary tract symptoms and the metabolic syndrome: Results from the Boston Area Community Health Survey. J Urol 182: 616-625, 2009.
51. Takeuchi $\mathrm{H}$ and Aoyagi $\mathrm{T}$ : Clinical characteristics in urolithiasis formation according to body mass index. Biomed Rep 11: 38-42, 2019.

52. Brand JS, van der Tweel I, Grobbee DE, Emmelot-Vonk MH and van der Schouw YT: Testosterone, sex hormone-binding globulin and the metabolic syndrome: A systematic review and meta-analysis of observational studies. Int J Epidemiol 40: 189-207, 2011.

53. TsujimuraA,MiyagawaY,TakezawaK,OkudaH,FukuharaS,KiuchiH, Takao T, Yamamoto R, Nishida M, Yamauchi-Takihara K, et al: Is low testosterone concentration a risk factor for metabolic syndrome in healthy middle-aged men? Urology 82: 814-819, 2013.

54. Corona G, Monami M, Rastrelli G, Aversa A, Tishova Y, Saad F, Lenzi A, Forti G, Mannucci E and Maggi M: Testosterone and metabolic syndrome: A meta-analysis study. J Sex Med 8: 272-283, 2011.

This work is licensed under a Creative Commons Attribution-NonCommercial-NoDerivatives 4.0 International (CC BY-NC-ND 4.0) License. 